\title{
Pragmatic Analysis on Staff Related Issues in Selected Hospitals
}

\author{
K. Roja ${ }^{1}$, G.D.V.Kusuma ${ }^{2} \&$ B. Ravi Kumar $^{3}$ \\ ${ }^{1}$ Department of MBA - Godavari Institute of Engineering and Technology, India \\ ${ }^{2}$ Research Scholar - Rayalaseema University, India \\ ${ }^{3}$ Department of MBA - Amrita Sai Institute of Science and Technology, India \\ Correspondence: B. Ravi Kumar, Department of MBA - Amrita Sai Institute of Science and Technology, India, \\ Email: ravi9949418650@yahoo.com
}

Received: August 30, 2018

Accepted: August 19, 2018

Online Published: September 8, 2018

\begin{abstract}
For the efficient management of an organization, it is pertinent that personnel working in different capacities in the different departments make possible friendly relations. Superiors would remain superiors even if they are influenced by ego. The supervisors acting like a superior and behaving like an officer/administrator, the possibilities of degeneration in the relations can't be overruled. The service of hospitals based on the staff it is essential for all the personnel irrespective of the rank and position they hold make sincere and honest efforts to accomplish the organizational goals. The present study is an attempt to portray the staff related issues in selected hospitals like GEMS, KIMS, RIMS, GMR.
\end{abstract}

Keywords: Employees, Health Sector, Hospitals, Staff Related Issues.

\section{Introduction}

From time immemorial women have been working - working everywhere - at home, in fields, factories and many other workplaces. However, women as a distinct segment of workers emerged and got recognition only with the emergence of industrial production After the industrial revolution, the social situations changed throughout the world and so in India. The family no more remained a centre for production. Due to industrialization and urbanization new social norms and values emerged. Job opportunities, economic hardship and favorable cultural and social situation encouraged the women to seek employment outside the home.

After independence of Country the number of women to come out of their houses for work increased day by day. They also took the education. In the early period women were mostly engaged in unskilled or semi-skilled occupations, as ayahs, nurses, mid wives, water women, cooks, domestic servants, as laborers on construction sites, in agricultural farm and on plantations. But now they are increasingly being employed in services, industries, shops, establishments, offices and professional / technical occupations. This change enhanced the status of women on the one hand and Country prosperity on the other, but it gave rise to many problems and difficulties for them by way of exploitation, discrimination and dismal working conditions. They have to perform dual responsibilities respectively termed "reproductive" and productive. This is not an easy task for women to work at home and working place. The problems and difficulties got multiplied due to their peculiar social, biological and psychological conditions and due to their illiteracy and ignorance.

2. Purpose of the Study

- The purpose of the study is to analyze the staff related issues in selected hospitals like GEMS, KIMS, RIMS, GMR. 


\section{Results and Discussion}

\subsection{The Employee Get Help and Support to Need from Colleagues}

The hospital managers in this context are required to improve their relations with peers or colleagues. The solicit cooperation need to extend cooperation, the relationship with peers, assumes a place of outstanding significance. It is more expedient to discuss thing directly with the colleagues and more so in open honest fashion. To encourage colleague to go ahead with the new ideas when convince with their strong arguments and presentation.

Table 1: The employee get help and support to need from colleagues

\begin{tabular}{|c|c|c|c|c|c|c|c|c|c|c|c|}
\hline \multirow[t]{3}{*}{ Sl.No. } & \multirow[t]{3}{*}{ Opinion } & \multicolumn{4}{|c|}{ Public } & \multicolumn{4}{|c|}{ Private } & \multirow{2}{*}{\multicolumn{2}{|c|}{ Total }} \\
\hline & & \multicolumn{2}{|c|}{ GEMS } & \multicolumn{2}{|c|}{ KIMS } & \multicolumn{2}{|c|}{ RIMS } & \multicolumn{2}{|c|}{ GMR } & & \\
\hline & & $\mathrm{F}$ & $\%$ & $\mathrm{~F}$ & $\%$ & $\mathrm{~F}$ & $\%$ & $\mathrm{~F}$ & $\%$ & $\mathrm{~F}$ & $\%$ \\
\hline 1. & Strongly Disagree & 02 & 3.3 & 01 & 2.0 & 05 & 3.3 & 02 & 2.5 & 10 & 2.94 \\
\hline 2. & Disagree & 03 & 5.0 & 03 & 6.0 & 08 & 5.3 & 06 & 7.5 & 20 & 5.88 \\
\hline 3. & Neutral & 09 & 15.0 & 10 & 20.0 & 26 & 17.3 & 15 & 18.8 & 60 & 17.64 \\
\hline 4. & Agree & 42 & 70.0 & 34 & 68.0 & 102 & 68.0 & 52 & 65.0 & 230 & 67.64 \\
\hline 5. & Strongly Agree & 04 & 6.6 & 02 & 4.0 & 09 & 6.1 & 05 & 6.3 & 20 & 5.88 \\
\hline & Total & 60 & 100 & 50 & 100 & 150 & 100 & 80 & 100 & 340 & 100 \\
\hline
\end{tabular}

From the above Table designs about The employee get help and support from colleagues has shown the results of four hospitals are GEMS, KIMS, RIMS, GMR. In the four hospitals strongly Disagree are 10\%, Disagree are 5.88\%, Neutral are $17.64 \%$, Agree are 67.64\%, Strongly Agree are 5.88\%. In GEMS the respondents Strongly Agree are 6.6\%, Agree are 70\%, Neutral are 15\%, Disagree are 5\% and Strongly Disagree are 3.3\%. In KIMS the respondents Strongly Agree are 4\%, Agreeare 68\%, Neutral are 20\%, Disagree are 6\%, and Strongly Disagree are 2\%. In RIMS the respondents Strongly Agree are 6.1\%, Agree are 68\%, Neutral are 17.3\%, Disagree are 5.3\% and Strongly Disagree are 3.3\%. In GMR the respondents Strongly Agree are 6.3\%, Agree are 65\%, Neutral are $18.8 \%$, Disagree are $7.5 \%$ and Strongly Disagree are $2.5 \%$.

\subsection{The Employee Have Sufficient Opportunities to Question Managers about Changes at Work}

The hospital managers with high communicative ability may be successful in developing good relations with colleagues/peers. At each and every stage their need cooperation of different department for discharging their responsibilities and opportunities efficiently and successfully.

Table 2: The employee have sufficient opportunities to question managers about changes at work

\begin{tabular}{|c|c|c|c|c|c|c|c|c|c|c|c|}
\hline \multirow[t]{3}{*}{ S.No. } & \multirow[t]{3}{*}{ Opinion } & \multicolumn{4}{|c|}{ Public } & \multicolumn{4}{|c|}{ Private } & \multirow{2}{*}{\multicolumn{2}{|c|}{ Total }} \\
\hline & & \multicolumn{2}{|c|}{ GEMS } & \multicolumn{2}{|c|}{ KIMS } & \multicolumn{2}{|c|}{ RIMS } & \multicolumn{2}{|c|}{ GMR } & & \\
\hline & & $\mathrm{F}$ & $\%$ & $\mathrm{~F}$ & $\%$ & $\mathrm{~F}$ & $\%$ & $\mathrm{~F}$ & $\%$ & $\mathrm{~F}$ & $\%$ \\
\hline 1. & Strongly Disagree & 25 & 41.7 & 19 & 38.0 & 57 & 38.0 & 29 & 36.3 & 130 & 38.23 \\
\hline 2. & Disagree & 13 & 21.7 & 12 & 24.0 & 34 & 22.7 & 21 & 26.3 & 80 & 23.52 \\
\hline 3. & Neutral & 11 & 18.3 & 10 & 20.0 & 32 & 21.3 & 17 & 21.3 & 70 & 20.58 \\
\hline 4. & Agree & 09 & 15.0 & 08 & 16.0 & 22 & 14.7 & 11 & 13.8 & 50 & 14.70 \\
\hline \multirow[t]{2}{*}{5.} & Strongly Agree & 02 & 3.3 & 01 & 2.0 & 05 & 3.3 & 02 & 2.5 & 10 & 2.94 \\
\hline & Total & 60 & 100 & 50 & 100 & 150 & 100 & 80 & 100 & 340 & 100 \\
\hline
\end{tabular}

From the above Table designs about The employee have sufficient opportunities to question managers about changes at work has shown the results of four hospitals are GEMS, KIMS, RIMS, GMR. In the four hospitals strongly Disagree are 38.23\%, Disagree are 23.52\%, Neutral are 20.58\%, Agree are 14.7\%, Strongly Agree are 2.94\%. In GEMS the respondents Strongly Agree are 3.3\%, Agree are 15\%, Neutral are 18.3\%, Disagree are $21.7 \%$ and Strongly Disagree are 41.7\%. In KIMS the respondents Strongly Agree are 2\%, Agree are 16\%, Neutral are 20\%, Disagree are 24\%, and Strongly Disagree are 38\%. In RIMS the respondents Strongly Agree are 3.3\%, Agree are 14.7\%, Neutral are 21.3\%, Disagree are $22.7 \%$ and Strongly Disagree are 38\%. In GMR the respondents Strongly Agree are 2.5\%, Agree are 13.8\%, Neutral are 21.3\%, Disagree are 26.3\% and Strongly Disagree are $36.3 \%$. 


\subsection{The Employee Receive Respect at Work They Deserve From Colleagues}

Sound management of behavior makes the way of friendly and harmonious relations, a prerequisite for efficiency generation. The hospitals to find team, it is pertinent that the hospital managers make sincere efforts to improve relationship. Since the hospital personnel bear the responsibility of serving the patients, it is essential that hospital personnel in general are found liberal to the sweet relationship with the patients.

Table 3: The employee receive respect at work they deserve from colleagues

\begin{tabular}{|c|c|c|c|c|c|c|c|c|c|c|c|}
\hline \multirow[t]{3}{*}{ S.No. } & \multirow[t]{3}{*}{ Opinion } & \multicolumn{4}{|c|}{ Public } & \multicolumn{4}{|c|}{ Private } & \multirow{2}{*}{\multicolumn{2}{|c|}{ Total }} \\
\hline & & \multicolumn{2}{|c|}{ GEMS } & \multicolumn{2}{|c|}{ KIMS } & \multicolumn{2}{|c|}{ RIMS } & \multicolumn{2}{|c|}{ GMR } & & \\
\hline & & $\bar{F}$ & $\%$ & $\bar{F}$ & $\%$ & $\mathrm{~F}$ & $\%$ & $\bar{F}$ & $\%$ & $\mathrm{~F}$ & $\%$ \\
\hline 1. & Strongly Disagree & 02 & 3.3 & 01 & 2.0 & 05 & 3.3 & 02 & 2.5 & 10 & 2.94 \\
\hline 2. & Disagree & 08 & 13.3 & 10 & 20.0 & 24 & 16.0 & 18 & 22.5 & 60 & 17.64 \\
\hline 3. & Neutral & 08 & 13.3 & 05 & 10.0 & 19 & 12.7 & 08 & 10.0 & 40 & 11.76 \\
\hline 4. & Agree & 22 & 36.7 & 20 & 40.0 & 57 & 38.0 & 31 & 38.8 & 130 & 38.23 \\
\hline \multirow[t]{2}{*}{5.} & Strongly Agree & 20 & 33.3 & 14 & 28.0 & 45 & 30.0 & 21 & 26.3 & 100 & 29.41 \\
\hline & Total & 60 & 100 & $\overline{50}$ & 100 & 150 & 100 & 80 & 100 & 340 & 100 \\
\hline
\end{tabular}

From the above Table designs about The employee receive respect at work they deserve from colleagues has shown the results of four hospitals are GEMS, KIMS, RIMS, GMR. In the four hospitals strongly Disagree are 2.94\%, Disagree are $17.64 \%$, Neutral are $11.76 \%$, Agree are $38.23 \%$, Strongly Agree are $29.41 \%$. In GEMS the respondents Strongly Agree are 33.3\%, Agree are 36.7\%, Neutral are $13.3 \%$, Disagree are $13.3 \%$ and StronglyDisagree are 3.3\%. In KIMS the respondents Strongly Agree are 28\%, Agreed are 40\%, Neutral are 10\%, Disagree are 20\%, and Strongly Disagree are 5\%. In RIMS the respondents Strongly Agree are 30\%, Agreed are $38 \%$, Neutral are 12.7\%, Disagree are 16\% and Strongly Disagree are 3.3\%. In GMR the respondents Strongly Agree are 26.3\%, Agree are 38.8\%, Neutral are 10\%, Disagree are 22.5\% and Strongly Disagree are 2.5\%. 3.4 Staff Are Always Consulted About Change of Work

The staff is related to the quality of the environment at the work place. It makes it essential that the hospital personnel find the work environment friendly or conducive. The availability of suitable infrastructural facilities and the behaviour of the superior to the subordinates and become significant in the context.

Table 4: Staff are always consulted about change of work

\begin{tabular}{|c|c|c|c|c|c|c|c|c|c|c|c|}
\hline \multirow[t]{3}{*}{ S. No. } & \multirow[t]{3}{*}{ Opinion } & \multicolumn{4}{|c|}{ Public } & \multicolumn{4}{|c|}{ Private } & \multirow{2}{*}{\multicolumn{2}{|c|}{ Total }} \\
\hline & & \multicolumn{2}{|c|}{ GEMS } & \multicolumn{2}{|c|}{ KIMS } & \multicolumn{2}{|c|}{ RIMS } & \multicolumn{2}{|c|}{ GMR } & & \\
\hline & & $\mathrm{F}$ & $\%$ & $\mathrm{~F}$ & $\%$ & $\mathrm{~F}$ & $\%$ & $\mathrm{~F}$ & $\%$ & $\mathrm{~F}$ & $\%$ \\
\hline 1. & Strongly Disagree & 02 & 3.33 & 02 & 4 & 10 & 6.67 & 8 & 10 & 22 & 6.47 \\
\hline 2. & Disagree & 05 & 8.33 & 4 & 8 & 12 & 8 & 3 & 3.75 & 24 & 7.05 \\
\hline 3. & Neutral & 10 & 16.67 & 3 & 6 & 10 & 6.67 & 8 & 10 & 31 & 9.11 \\
\hline 4. & Agree & 30 & 50 & 20 & 40 & 69 & 46 & 31 & 38.75 & 150 & 44.12 \\
\hline 5. & Strongly Agree & 13 & 21.67 & 21 & 42 & 49 & 32.67 & 30 & 37.5 & 113 & 33.23 \\
\hline & Total & 60 & 100 & 50 & 100 & 150 & 100 & 80 & 100 & 340 & 100 \\
\hline
\end{tabular}

From the above Table designs about Staff are always consulted about change of work shown the results of four hospitals are GEMS, KIMS, RIMS, and GMR. In the four hospitals strongly Disagree are $6.47 \%$, Disagree are $7.05 \%$, Neutral are $9.11 \%$, Agree are $44.12 \%$, Strongly Agree are $33.23 \%$. In GEMS the respondents Strongly Agree are $21.67 \%$, Agree are $50 \%$, Neutral are $16.67 \%$, Disagree are $8.33 \%$ and strongly Disagree are $3.33 \%$. In KIMS the respondents Strongly Agree are 42\%, Agree re 40\%, Neutral are 6\%, Disagree are 8\%, and Strongly Disagree are 4\%. In RIMS the respondents Strongly Agree are 32.67\%, Agree are 46\%, Neutral are 6.67\%, Disagree are $8 \%$ and strongly Disagree are 6.67\%. In GMR the respondents are Strongly Agree are 37.5\%, Agreed are $38.75 \%$, Neutral are 10\%, Disagree are 3.75\% and Strongly Disagree are 10\%.

3.5 The Employee Can Talk To Line Managers about Something That Has Upset or Annoyed About Their Work The employee makes its essential go through the problem of relationship assign an overriding priority to this dimension and make best of their efforts to make relationship, friendly, cohesive which in albeit the difficult tasks are performed successfully. 
Table 5: The employee can talk to line managers about something that has upset or annoyed about their work

\begin{tabular}{|c|c|c|c|c|c|c|c|c|c|c|c|}
\hline \multirow[t]{3}{*}{ Sl.No. } & \multirow[t]{3}{*}{ Opinion } & \multicolumn{4}{|c|}{ Public } & \multicolumn{4}{|c|}{ Private } & \multirow{2}{*}{\multicolumn{2}{|c|}{ Total }} \\
\hline & & \multicolumn{2}{|c|}{ GEMS } & \multicolumn{2}{|c|}{ KIMS } & \multicolumn{2}{|c|}{ RIMS } & \multicolumn{2}{|c|}{ GMR } & & \\
\hline & & $\mathrm{F}$ & $\%$ & $\mathrm{~F}$ & $\%$ & $\mathrm{~F}$ & $\%$ & $\mathrm{~F}$ & $\%$ & $\mathrm{~F}$ & $\%$ \\
\hline 1. & Strongly Disagree & 4 & 6.65 & 0 & 0 & 12 & 8 & 15 & 18.75 & 31 & 9.11 \\
\hline 2. & Disagree & 5 & 8.33 & 7 & 14 & 18 & 12 & 20 & 25 & 50 & 14.70 \\
\hline 3. & Neutral & 5 & 8.33 & 6 & 12 & 21 & 14 & 0 & 0 & 32 & 9.41 \\
\hline 4. & Agree & 36 & 60 & 26 & 52 & 86 & 57.33 & 35 & 43.75 & 183 & 53.82 \\
\hline \multirow[t]{2}{*}{5.} & Strongly Agree & 10 & 16.67 & 11 & 22 & 13 & 8.67 & 10 & 12.5 & 44 & 12.94 \\
\hline & Total & 60 & 100 & 50 & 100 & 150 & 100 & 80 & 100 & 340 & 100 \\
\hline
\end{tabular}

From the above Table illustrates about Staff are always consulted about change of work shown the results of four hospitals are GEMS, KIMS, RIMS, GMR. In the four hospitals strongly Disagree are 9.11\%, Disagree are 14.70\%, Neutral are 9.41\%, Agree are 53.82\%, Strongly Agree are 12.94\%. In GEMS the respondents Strongly Agree are $16.67 \%$, Agree are 60\%, Neutral are 8.33\%, Disagree are 8.33\% and Strongly Disagree are 6.67\%. In KIMS the respondents Strongly Agree are 22\%, Agreeare 52\%, Neutral are 12\%, Disagree are 14\%, and Strongly Disagree are nil. In RIMS the respondents Strongly Agree are 8.67\%, Agree are 57.33\%, Neutral are 14\%, Disagree are 12\% and Strongly Disagree are 8\%. In GMR the respondents Strongly Agree are 12.5\%, Agree are 43.75\%, Neutral are nil, Disagree are $25 \%$ and Strongly Disagree are $18.75 \%$.

3.6 The Employee Working Time Can Be Flexible

The nurses and sisters need to work with their service motto. They also found personally committed but the existing scenario and the increasing degeneration in the environment at the work place may disturb them and to counter the same, they need to be strong enough to face the multidimensional changes.

Table 6: The employee working time can be flexible

\begin{tabular}{|c|c|c|c|c|c|c|c|c|c|c|c|}
\hline \multirow[t]{3}{*}{ S.No. } & \multirow[t]{3}{*}{ Opinion } & \multicolumn{4}{|c|}{ Public } & \multicolumn{4}{|c|}{ Private } & \multirow{2}{*}{\multicolumn{2}{|c|}{ Total }} \\
\hline & & \multicolumn{2}{|c|}{ GEMS } & \multicolumn{2}{|c|}{ KIMS } & \multicolumn{2}{|c|}{ RIMS } & \multicolumn{2}{|c|}{ GMR } & & \\
\hline & & $\bar{F}$ & $\%$ & $\mathrm{~F}$ & $\%$ & $\mathrm{~F}$ & $\%$ & $\bar{F}$ & $\%$ & $\mathrm{~F}$ & $\%$ \\
\hline 1. & Strongly Disagree & 9 & 15 & 10 & 20 & 4 & 2.67 & 8 & 10 & 31 & 9.11 \\
\hline 2. & Disagree & 8 & 13.33 & 6 & 12 & 5 & 3.33 & 12 & 15 & 31 & 9.11 \\
\hline 3. & Neutral & 5 & 8.33 & 0 & 0 & 15 & 10 & 10 & 12.5 & 30 & 8.82 \\
\hline 4. & Agree & 28 & 41.17 & 22 & 44 & 90 & 60 & 28 & 35 & 168 & 49.41 \\
\hline 5. & Strongly Agree & 10 & 16.67 & 12 & 24 & 36 & 24 & 22 & 27.5 & 80 & 23.52 \\
\hline & Total & 60 & 100 & 50 & 100 & 150 & 100 & 80 & 100 & 340 & 100 \\
\hline
\end{tabular}

From the above Table examines about Staff are always consulted about change of work shown the results of four hospitals are GEMS, KIMS, RIMS, GMR. In the four hospitals strongly Disagree are 9.11\%, Disagree are 9.11\%, Neutral are $8.82 \%$, Agree are 49.41\%, Strongly Agree are 23.52\%. In GEMS the respondents Strongly Agree are 16.67\%, Agree are 41.17\%, Neutral are 8.33\%, Disagree are $13.33 \%$ and Strongly Disagree are 15\%. In KIMS the respondents Strongly Agree are 24\%, Agreed are 44\%, Neutral are nil, Disagree are 12\%, and Strongly Disagree are 20\%. In RIMS the respondents Strongly Agree are 24\%, Agree are60\%, Neutral are 10\%, Disagree are 3.33\% and Strongly Disagree are 2.67\% In GMR the respondents are Strongly Agree are 27.5\%, Agree are 35\%, Neutral are $12.5 \%$, Disagree are $15 \%$ and Strongly Disagree are $10 \%$.

\subsection{The Colleagues Are Willing To Listen Their Work Related Problems of the Employees}

The employee can share the attending meeting, seminar and workshop. This would help them in adding some new dimensions to their relationship. The selection and perception of the evaluation process undertaken by the employee may also be shared by the supervisor. All the efforts for performance evaluation should be reviewed by the supervisor. 
Table 7: The colleagues are willing to listen their work related problems of the employees

\begin{tabular}{|c|c|c|c|c|c|c|c|c|c|c|c|}
\hline \multirow{3}{*}{ S.No. } & \multirow{3}{*}{ Opinion } & \multicolumn{4}{|c|}{ Public } & \multicolumn{4}{|c|}{ Private } & \multirow{2}{*}{\multicolumn{2}{|c|}{ Total }} \\
\hline & & \multicolumn{2}{|c|}{ GEMS } & \multicolumn{2}{|c|}{ KIMS } & \multicolumn{2}{|c|}{ RIMS } & \multicolumn{2}{|c|}{ GMR } & & \\
\hline & & $\mathrm{F}$ & $\%$ & $\bar{F}$ & $\%$ & $\mathrm{~F}$ & $\%$ & $\mathrm{~F}$ & $\%$ & $\mathrm{~F}$ & $\%$ \\
\hline 1. & Strongly Disagree & 0 & 0 & 0 & 0 & 0 & 0 & 0 & 0 & 0 & 0 \\
\hline 2. & Disagree & 04 & 6.7 & 02 & 4.0 & 10 & 6.7 & 04 & 5.0 & 20 & 5.88 \\
\hline 3. & Neutral & 30 & 50.0 & 26 & 52.0 & 72 & 48.0 & 42 & 52.5 & 170 & 50 \\
\hline 4. & Agree & 16 & 26.7 & 12 & 24.0 & 42 & 28.0 & 20 & 25.0 & 90 & 26.47 \\
\hline \multirow[t]{2}{*}{5.} & Strongly Agree & 10 & 16.7 & 10 & 20.0 & 26 & 17.3 & 14 & 17.5 & 60 & 17.64 \\
\hline & Total & 60 & 100 & 50 & 100 & 150 & 100 & 80 & 100 & 340 & 100 \\
\hline
\end{tabular}

From the above Table examines about The colleagues are willing to listen their work related problems of the employees shown the results of four hospitals are GEMS, KIMS, RIMS, GMR. In the four hospitals strongly Disagree are nil, Disagree are 5.88\%, Neutral are 50\%, Agree are 26.47\%, Strongly Agree are 17.64\%. In GEMS the respondents Strongly Agree are 16.7\%, Agree with 26.7\%, Neutral are 50\%, Disagree are 6.7\% and Strongly Disagree are nil. In KIMS the respondents Strongly Agree are 20\%, Agreed are 24\%, Neutral are 52\%, Disagree are $4.0 \%$, and Strongly Disagree are nil. In RIMS the respondents are Strongly Agree are 17.3\%, Agree are 28\%, Neutral are $48 \%$, Disagree are $6.7 \%$ and Strongly Disagree are nil. In GMR the respondents Strongly Agree are $17.5 \%$, Agree are 25\%, Neutral 52.5\%, Disagree are 5\% and Strongly Disagree are nil.

3.8 When changes are made at work they are clear how they work out in practice

The changes in this context bear the responsibility of make it sure that the relationship with the superiors and subordinates should be working environment friendly.

Table 8: When changes are made at work they are clear how they work out in practice

\begin{tabular}{|c|c|c|c|c|c|c|c|c|c|c|c|}
\hline \multirow{3}{*}{ S.No. } & \multirow{3}{*}{ Opinion } & \multicolumn{4}{|c|}{ Public } & \multicolumn{4}{|c|}{ Private } & \multirow{2}{*}{\multicolumn{2}{|c|}{ Total }} \\
\hline & & \multicolumn{2}{|c|}{ GEMS } & \multicolumn{2}{|c|}{ KIMS } & \multicolumn{2}{|c|}{ RIMS } & \multicolumn{2}{|c|}{ GMR } & & \\
\hline & & $\mathrm{F}$ & $\%$ & $\mathrm{~F}$ & $\%$ & $\mathrm{~F}$ & $\%$ & $\mathrm{~F}$ & $\%$ & $\mathrm{~F}$ & $\%$ \\
\hline 1. & Strongly Disagree & 5 & 8.33 & 12 & 24 & 5 & 3.33 & 10 & 12.5 & 32 & 9.41 \\
\hline 2. & Disagree & 10 & 16.67 & 0 & 0 & 20 & 13.33 & 10 & 12.5 & 40 & 11.76 \\
\hline 3. & Neutral & 7 & 11.67 & 6 & 12 & 10 & 6.67 & 10 & 12.5 & 33 & 9.70 \\
\hline 4. & Agree & 18 & 30 & 20 & 40 & 80 & 53.33 & 40 & 50 & 158 & 46.4 \\
\hline \multirow[t]{2}{*}{5.} & Strongly Agree & 20 & 33.3 & 12 & 24 & 35 & 23.33 & 10 & 12.5 & 77 & 22.64 \\
\hline & Total & 60 & 100 & 50 & 100 & 150 & 100 & 80 & 100 & 340 & 100 \\
\hline
\end{tabular}

From the above Table examines about when changes are made at work they are clear how they work out in practice shown the results of four hospitals are GEMS, KIMS, RIMS, GMR. In the four hospitals strongly Disagree are $9.411 \%$, Disagree are $11.76 \%$, Neutral are 9.70\%, Agree are 46.4\%, Strongly Agree are 22.64\%. In GEMS the respondents Strongly Agree are 33.3\%, Agree are30\%, Neutral are 11.67\%, Disagree are 16.67\% and Strongly Disagreed are 8.33\%. In KIMS the respondents Strongly Agree are 24\%, Agreed are 40\%, Neutral are $12 \%$, Disagree are nil, and Strongly Disagree are 24\%. In RIMS the respondents Strongly Agree are 23.33\%, Agree are 53.33\%, Neutral are 6.67\%, Disagree are 13.33\% and Strongly Disagree are 3.33\%. In GMR the respondents are Strongly Agree are 12.5\%, Agree are 50\%, Neutral are 12.5\%, Disagreed are 12.5\% and Strongly Disagree are $12.5 \%$.

\subsection{The Employee Get Support through Emotionally Demanding Work}

The nurses are professionally sound and personally committed and it is due to the fact that the government hospitals in particular are found existent despite of number of odds. Despite of number of degeneration in the process if there is something left in the government hospitals it is due to the commitment of profession. 
Table 9: The employee is getting support through emotionally demanding work

\begin{tabular}{|c|c|c|c|c|c|c|c|c|c|c|c|}
\hline \multirow[t]{3}{*}{ S.No. } & \multirow[t]{3}{*}{ Opinion } & \multicolumn{4}{|c|}{ Public } & \multicolumn{4}{|c|}{ Private } & \multirow{2}{*}{\multicolumn{2}{|c|}{ Total }} \\
\hline & & \multicolumn{2}{|c|}{ GEMS } & \multicolumn{2}{|c|}{ KIMS } & \multicolumn{2}{|c|}{ RIMS } & \multicolumn{2}{|c|}{ GMR } & & \\
\hline & & $\mathrm{F}$ & $\%$ & $\mathrm{~F}$ & $\%$ & $\mathrm{~F}$ & $\%$ & $\bar{F}$ & $\%$ & $\mathrm{~F}$ & $\%$ \\
\hline 1. & Strongly Disagree & 3 & 5 & 4 & 8 & 12 & 8 & 12 & 15 & 31 & 9.11 \\
\hline 2. & Disagree & 7 & 11.67 & 6 & 12 & 18 & 12 & 10 & 12.5 & 41 & 12.05 \\
\hline 3. & Neutral & 6 & 10 & 4 & 8 & 8 & 5.33 & 8 & 10 & 26 & 7.64 \\
\hline 4. & Agree & 22 & 36.67 & 26 & 52 & 89 & 59.33 & 33 & 41.25 & 170 & 50 \\
\hline \multirow[t]{2}{*}{5.} & Strongly Agree & 12 & 20 & 10 & 20 & 23 & 15.33 & 07 & 8.75 & 62 & 18.23 \\
\hline & Total & 60 & 100 & 50 & 100 & 150 & 100 & 80 & 100 & 340 & 100 \\
\hline
\end{tabular}

From the above Table examines about The employee get supported through emotionally demanding work shown the results of four hospitals are GEMS, KIMS, RIMS, GMR. In the four hospitals strongly Disagree are 9.11\%, Disagree are 12.05\%, Neutral are 7.64\%, Agree are 50\%, Strongly Agree are 18.23\%. In GEMS the respondents Strongly Agree are 20\%, Agree are 36.67\%, Neutral are 10\%, Disagree are $11.67 \%$ and Strongly Disagree are 5\%. In KIMS the respondents Strongly Agree are 20\%, Agreeare52\%, Neutral are 8\%, Disagree are 12\%, and Strongly Disagree are 8\%. In RIMS the respondents Strongly Agree are 15.33\%, Agree are59.33\%, Neutral are 5.33\%, Disagree are $12 \%$ and Strongly Disagree are $8 \%$. In GMR the respondents Strongly Agree are 8.75\%, Agreed are $41.25 \%$, Neutral are 10\%, Disagree are $12.5 \%$ and Strongly Disagree are $15 \%$.

3.10 Relationship at Work Strained

To be more specific in government hospitals to find (large almost) all the employees promoting insincerity, the nurses and sisters find it difficult to work. It is against the employee find that the case of increasing insincerity even among the nurses.

Table 10: Relationship at work strained

\begin{tabular}{|c|c|c|c|c|c|c|c|c|c|c|c|}
\hline \multirow{3}{*}{ S.No. } & \multirow{3}{*}{ Opinion } & \multicolumn{4}{|c|}{ Public } & \multicolumn{4}{|c|}{ Private } & \multirow{2}{*}{\multicolumn{2}{|c|}{ Total }} \\
\hline & & \multicolumn{2}{|c|}{ GEMS } & \multicolumn{2}{|c|}{ KIMS } & \multicolumn{2}{|c|}{ RIMS } & \multicolumn{2}{|c|}{ GMR } & & \\
\hline & & $\mathrm{F}$ & $\%$ & $\mathrm{~F}$ & $\%$ & $\mathrm{~F}$ & $\%$ & $\mathrm{~F}$ & $\%$ & $\mathrm{~F}$ & $\%$ \\
\hline 1. & Strongly Disagree & 6 & 10 & 6 & 12 & 16 & 10.67 & 10 & 12.5 & 38 & 11.17 \\
\hline 2. & Disagree & 10 & 16.67 & 6 & 12 & 8 & 5.33 & 10 & 12.5 & 34 & 10 \\
\hline 3. & Neutral & 7 & 11.67 & 0 & 0 & 10 & 6.67 & 12 & 15 & 29 & 8.52 \\
\hline 4. & Agree & 27 & 45 & 25 & 50 & 82 & 54.67 & 33 & 41.25 & 167 & 49.11 \\
\hline \multirow[t]{2}{*}{5.} & Strongly Agree & 10 & 16.67 & 13 & 26 & 34 & 22.67 & 15 & 18.75 & 72 & 21.17 \\
\hline & Total & 60 & 100 & 50 & 100 & 150 & 100 & 80 & 100 & 340 & 100 \\
\hline
\end{tabular}

From the above Table dictates about Relationship at work strained shown the results of four hospitals are GEMS, KIMS, RIMS, GMR. In the four hospitals strongly Disagree are $11.17 \%$, Disagree are $10 \%$, Neutral are $8.52 \%$, Agree are $49.11 \%$, Strongly Agree are $21.17 \%$. In GEMS the respondents are Strongly Agree are $16.67 \%$, Agree are $45 \%$, Neutral are $11.67 \%$, Disagree are $16.67 \%$ and Strongly Disagree are 10\%. In KIMS the respondents Strongly Agree are 26\%, Agree are 50\%, Neutral are nil, Disagree are 12\%, and Strongly Disagree are $12 \%$. In RIMS the respondents Strongly Agree are 22.67\%, Agreed are 54.67\%, Neutral are 6.67\%, Disagree are 5.53\% and Strongly Disagree are 10.67. In GMR the respondents Strongly Agree are $18.75 \%$, Agreed are 41.25\%, Neutral are $15 \%$, Disagreed are $12.5 \%$ and Strongly Disagree are $12.5 \%$.

References

Ziaul Huq.(1996). A TQM evaluation framework for hospitals-observations from a study. International Journal of Quality and Reliability Management .13(6), 59-76.

Zydziunaite Vilma and Katiliute Egle.(2007).Improving motivation among healthcare workers in private healthcare organizations- A perspective of nursing personnel. Baltic Journal of Management. 2(2).

Tom Cox, Sue Cox and Dr. Amanda Griffiths "Work-related stress in nursing: Controlling the risk to health" Working paper

Thomas M. Gehring, Jeannette Widmer, Oskar Bänziger \& Daniel Marti.(2002). Quality of Work and Need for Supervision Among Physicians and Nurses of a Pediatric Intensive Care Unit. 7,595 
Thomas Joseph McCabe and Thomas N Garavan.(2008).A study of the drivers of commitment amongst nurses the salience of training, development and career issues", Journal of European Industrial Training. 32(7), Teresa M et el. (1996). Assessing the work environment for creativity. The Academy of Management Journal, 39(5), 1154-1184.

\section{Copyrights}

Copyright for this article is retained by the author(s), with first publication rights granted to the journal.

This is an open-access article distributed under the terms and conditions of the Creative Commons Attribution license (http://creativecommons.org/licenses/by/4.0/) 